\title{
Arborização viária e sua relação com a infraestrutura urbana em Almenara, MG, Brasil
}

\author{
Urban tree relating to urban infrastructure in Almenara, MG,
} Brazil

\section{Arborización vial y su relación con la infraestructura urbana en Almenara, MG, Brasil}

\author{
Marival Pereira de Sousa \\ https:/ / orcid.org/0000-0001-8131-3479 \\ marival.sousa@ifnmg.edu.br
}

Instituto Federal do Norte de Minas, IFNMG, Campus de Almenara, MG

Allívia Rouse Carregosa Rabbani https:/ / orcid.org/0000-0003-0564-7113

alliviarouse@ifba.edu.br

Instituto Federal de Educação Ciência e Tecnologia da Bahia, IFBA, Campus Porto Seguro, BA

Maria Otávia Silva Crepaldi

https:/ / orcid.org/0000-0003-3121-8857

mariaotavia@gmail.com

Universidade Federal do Vale do São Francisco, UFVSF, Senhor do Bonfim, BA

Arine Barbosa Ferreira da Silva http:/ / orcid.org/0000-0003-1580-0388

arinebarbosaf@gmail.com

Instituto Federal do Norte de Minas, IFNMG, Campus de Almenara, MG

Resumo: A arborização promove benefícios ambientais, porém a falta de planejamento pode promover conflitos urbanos. A presente pesquisa avaliou a arborização e diagnosticou os possíveis conflitos entre as árvores e a infraestrutura urbana em oito bairros de Almenara, MG. Foram identificados conflitos com rede elétrica, edificação e o trânsito de pessoas e veículos. Foram encontradas 2038 árvores pertencentes a 61 espécies, sendo $61 \%$ exóticas. As situações de maior desconforto para a mobilidade urbana foram das árvores posicionadas no leito carroçável (56\%), calçadas com largura inferior a 1,90 m (74\%), e média de altura de primeira bifurcação abaixo de 1,80 m, dentre outros. Foi verificado que a população necessita de orientação quanto à sua participação no manejo das árvores da cidade. Logo, este diagnóstico pode ajudar a subsidiar a revisão do plano diretor da cidade, e a criação de um futuro plano de 
gestão de arborização urbana no município.

Palavras-chave: Urbanização, arborização, mobilidade, planejamento urbano.

\begin{abstract}
Afforestation promotes environmental benefits, but a lack of planning can promote urban conflicts. This research evaluated afforestation and diagnosed the possible conflicts between trees and urban infrastructure in eight neighborhoods of Almenara, MG. Conflicts with the power grid, building, and the traffic of people and vehicles were identified. There were 2,038 trees belonging to 61 species, $61 \%$ exotic. The most uncomfortable situations for urban mobility were trees positioned on the street bed $(56 \%)$, sidewalks with a width of less than $1.90 \mathrm{~m}(74 \%)$, and an average height of the first fork below $1.80 \mathrm{~m}$, among others. It was observed that the population needs guidance regarding their participation in the management of the city's trees. Thus, this diagnosis may help support the review of the city's Master Plan and the creation of a future urban afforestation management plan in the municipality.
\end{abstract}

Keywords: Urbanization, afforestation, mobility, urban planning.

Resumen: La forestación promueve beneficios ambientales, pero la falta de planificación puede promover conflictos urbanos. Esta investigación evaluó la forestación y diagnosticó los posibles conflictos entre árboles e infraestructura urbana en ocho vecindarios de Almenara, MG. Se identificaron conflictos con la red eléctrica, la construcción y el tráfico de personas y vehículos. Había 2038 árboles pertenecientes a 61 especies, $61 \%$ exóticas. Las situaciones más incómodas para la movilidad urbana fueron los árboles colocados en las carreteras (56\%), las aceras con un ancho de menos de $1.90 \mathrm{~m}(74 \%)$ y la altura promedio de la primera horquilla por debajo de $1.80 \mathrm{~m}$, entre otros Se encontró que la población necesita orientación con respecto a su participación en el manejo de los árboles de la ciudad. Por lo tanto, este diagnóstico puede ayudar a respaldar la revisión del Plan Maestro de la ciudad y la creación de un futuro plan de manejo de forestación urbana en el municipio.

Palabras clave: Urbanización, forestación, movilidad, planificación urbana.

\title{
INTRODUÇÃO
}

O crescente processo de urbanização e a pressão antrópica apresentaram diversas consequências ambientalmente negativas, que em função da supressão da vegetação nativa, provocou a degradação de áreas naturais, motivada pela ocupação das zonas urbanas sem planejamento, causando perda da qualidade ambiental nas cidades (Imam \& Banerjee, 2016; Duarte, Angeoletto, Richard, Vacchiano, Leandro, Bohrer, \& Santos, 2017; Zamproni, Biondi, Maria, \& Louveira, 2018).

Em Minas Gerais o processo de urbanização vem aumentando desde 1960, principalmente nas regiões Norte e Nordeste do estado, onde o Vale do Jequitinhonha é a região menos urbanizada, formada por pequenas cidades. O próprio conceito de cidade pequena ainda é debatido em função da dificuldade em caracterizá-la e, em geral, estas cidades são pouco estudadas. Contudo, esses locais tem ganho novas proporções e interesse pela ciência geográfica (Manfio \& Benaduce, 2011; Oliveira, Pereira, Santos, Oliveira, \& Pompermayer, 2016).

Cidades pequenas podem apresentar vantagens quando comparadas com grandes espaços urbanos, uma vez que se pode ter um melhor controle de sua gestão. Em se 
tratando de áreas verdes, sempre há praças, avenidas ou ruas cuja arborização deve ser tratada com atenção.

Muitos benefícios são proporcionados pela presença de árvores, como a regulação da temperatura, sombreamento, controle da poluição sonora e atmosférica, manutenção e preservação da biodiversidade local, diminuição de enxurradas e enchentes, aumento da umidade do ar, valorização da paisagem proporcionando melhoria estética e psicológica aos habitantes (Companhia Energética de Minas Gerais [CEMIG], 2011; Lira Filho, 2012; Pagliari \& Dorigon, 2013).

Segundo Duarte, Angeoletto, Santos, Silva, Bohrer e Massad (2018), a expressão 'Arborização Urbana' foi utilizada a princípio no Brasil como tradução ao termo em inglês Urban Forest. Biondi (2008) explica que essa expressão se refere a toda vegetação que compõe o cenário ou a paisagem urbana, independente do porte, sendo um dos componentes vivos mais importantes da cidade. Para Duarte et al. (2018), esta deve compensar a perda de qualidade ambiental ocorrida no processo de transformação do espaço.

No entanto, a falta de planejamento para a implantação e manutenção de arborização acaba por prejudicar suas qualidades (Gonçalves \& Meneguetti, 2015). A arborização urbana deve ser planejada de acordo às necessidades locais e especificidades da flora e fauna do ambiente, com iniciativas voltadas a atender aos objetivos e realidade local, ultrapassando o elemento meramente estético, visto que a falta de planejamento pode ocasionar problemas por vezes irreversíveis, passando a representar um foco de conflito com a estrutura urbana e a biodiversidade local (Periotto, Pituco, Helmann, Santos, \& Bortolotti, 2016; Duarte et al., 2017).

Os problemas decorrentes pela falta de planejamento na arborização urbana podem ser representados por danos causados aos passeios públicos, prejuízos à mobilidade urbana, conflitos com as redes de eletrificação, obstrução da iluminação pública e danos causados às redes de água, esgoto sanitário e edificações. Também a utilização de espécies exóticas pode prejudicar a biodiversidade local.

Em função disso, o processo de arborização deve ser planejado pelo Poder Executivo Municipal para obter os elementos necessários à sua completa concepção, e o levantamento dos possíveis problemas e conflitos, tendo como requisito a implantação do plano diretor e a criação de leis voltadas a este fim (CEMIG, 2011; Periotto et al. 2016). Segundo Trichez (2008), para a implantação de qualquer atividade nessas circunstâncias são necessários critérios, como a escolha da espécie, local e técnicas de plantio, bem como a sua origem, o porte, o espaçamento etc.

Portanto este artigo se propõe a analisar a arborização viária da cidade de Almenara (MG) através de um levantamento quali-quantitativo, ou seja, identificar e quantificar as árvores presentes na área urbana do município, relacionadas com a infraestrutura urbana.

\section{MATERIAL E MÉTODOS}

A mesorregião do Vale do Jequitinhonha localiza-se no Nordeste de Minas e está dividida entre as microregiões do Alto, Médio e Baixo Jequitinhonha, onde o município 
de Almenara está inserido (Fig. 1). Com 2.308,6 km² de área urbana, Almenara está situada a $16^{\circ} 11^{\prime} 01^{\prime \prime}$ Sul e $40^{\circ} 41^{\prime} 40^{\prime \prime}$ Oeste, com altitude média de 187 metros. De seus 38.775 habitantes, 7.025 vivem na área rural e 31.750 na área urbana, com densidade populacional de $16,9 \mathrm{hab} . / \mathrm{km}^{2}$. A temperatura média anual é de $31^{\circ} \mathrm{C}$ conforme o Instituto Brasileiro de Geografia e Estatística (IBGE) (2010). Na classificação climática de Koeppen-Geiger, o clima da região é considerado como Aw, clima tropical de savana (Cerrado), com estação seca no inverno, e precipitação média de 950,1-1.050 mm.

Conforme dados apresentados no Plano Diretor do município (Lei n $1.133,2008$ ), Almenara apresenta quatro regiões fitofisionômicas, dentre elas a Floresta Estacional Semidecidual (Bioma Mata Atlântica), que ocupa maior parte do município (109.480 ha, 47,77\%), a Savana (Cerrado sensu stricto, 6.624 ha, 2,89\%), a Savana gramínea lenhosa (campo cerrado, 63 ha, 0,03\%) e a Floresta Estacional Decidual (Caatinga arbórea, 36 ha, $0,02 \%$ ), a qual correspondem a um total de 116.203 ha de flora nativa, correspondendo a $50,70 \%$ da área do município. A maior parte da terra é ocupada pela agricultura intensiva (Reboita, Rodrigues, Silva, \& Alves, 2015).

Figura 1. Área urbana de Almenara, MG, com destaque para a localização dos bairros e praças públicas

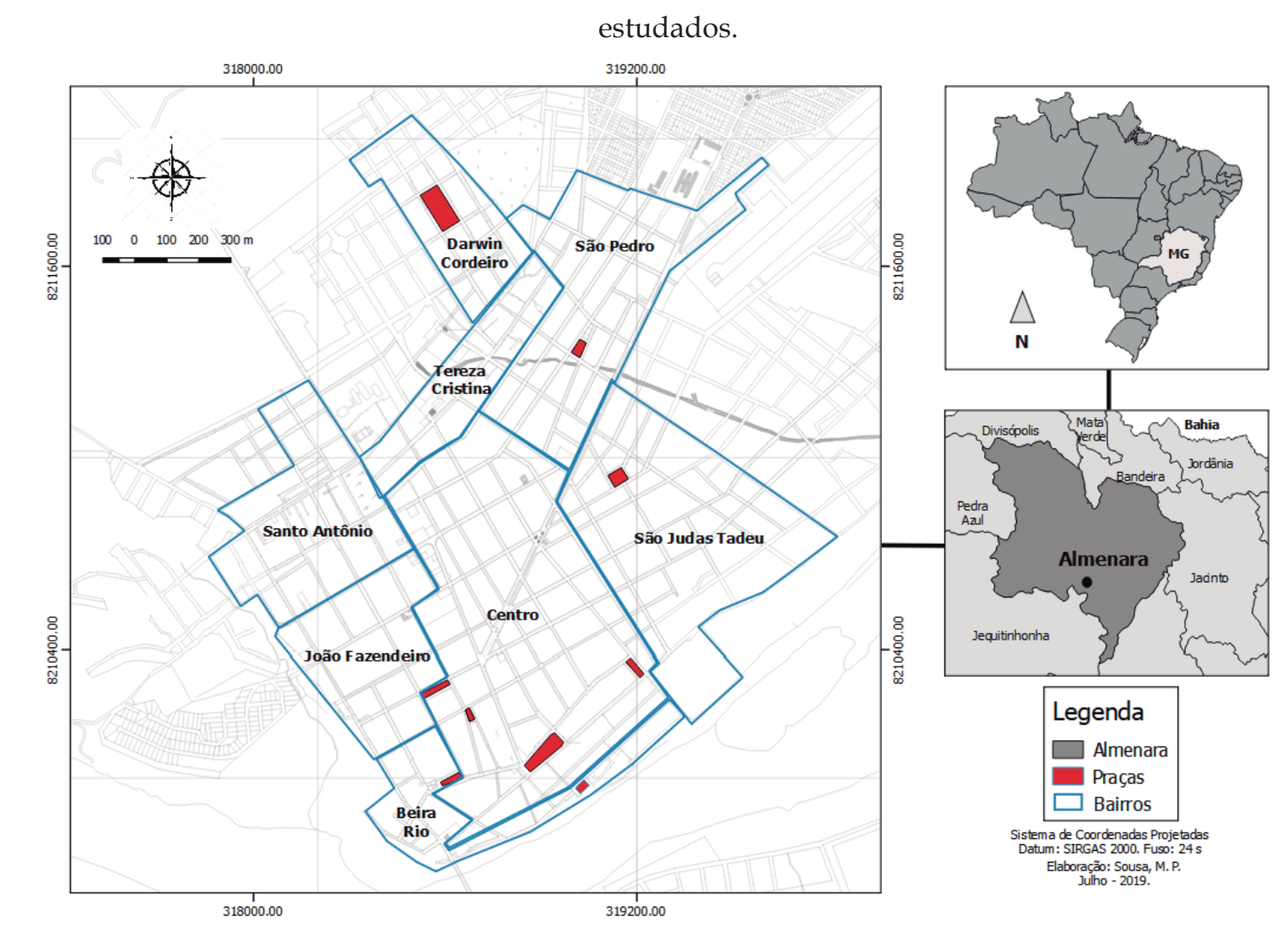

O Índice de Desenvolvimento Humano Municipal (IDHM) de Almenara é 0,642 (IBGE, 2019), considerado abaixo da média nacional $(0,727)$, refletindo assim as precárias condições dos componentes educação, esperança de vida ao nascer e renda na realidade vivenciada pela população local. Segundo Soares (2013), o Vale é colocado pela mídia como estereótipo de extrema pobreza e carência social, situação que está ligada aos baixos 
indicadores sociais e econômicos, que de fato retrataram os problemas locais. Porém o autor menciona que a região é caracterizada por uma identidade regional forte, rica e marcante nos seus aspectos histórico-cultural. Além disso, Fortunato (2011) destaca que, várias ações como a promoção do artesanato, do turismo e o fortalecimento da vida comunitária são propostas pelo Governo do Estado como forma de combate à pobreza na região.

A pesquisa foi realizada entre os meses de setembro de 2018 e junho de 2019, com o levantamento total das espécies arbóreas encontradas em oito bairros da cidade: Centro, Beira-rio, Darwin Cordeiro, João Fazendeiro, Santo Antônio, São Judas Tadeu, São Pedro, Tereza Cristina, áreas que correspondem a cerca de $60 \%$ do território habitado dentro do logradouro urbano da cidade.

Todas as árvores foram georreferenciadas através das coordenadas coletadas com a utilização de um GPS Garmin ${ }^{\circledast}$ Etrex 10 e fotografadas com a utilização de um aparelho smartphone Samsung Galaxy J6 ${ }^{\oplus}$. Foram anotados em formulários a condição do arruamento e da vegetação arbórea, a origem e porte das espécies, dados dendrométricos como diâmetro à altura do peito, diâmetro da copa, altura total dos indivíduos, altura da primeira bifurcação, e condição sanitária. Também foram anotados dados de espacialização como local onde a árvore estava posicionada, distância entre equipamentos e infraestrutura urbana, área livre da planta, condição do sistema radicular e o aspecto da poda sofrida também foram analisados.

Para obter a correta identificação botânica dos indivíduos, foram coletados ramos vegetativos e reprodutivos (quando presentes) a as exsicatas encaminhadas para identificação no herbário Professor Geraldo Carlos Pereira Pinto, da Universidade Federal do Sul da Bahia - Campus Sosígenes Costa.

O cálculo de frequência das espécies seguiu Oliveira, Ferreira, Lopes, Reis e Costa (2017), em que foram calculadas as frequências absoluta e relativa de toda população arbórea. A frequência absoluta do número de árvores refere-se ao somatório do número de indivíduos (n) de uma espécie (i).

A frequência relativa indica o percentual representativo de determinada espécie (i):

$F R_{i}=(n / N) * 100$

Onde $F R_{i}$ é a Frequência relativa do número de árvores, em percentagem;

$n_{i}$ é o número de indivíduos da espécie;

$\mathrm{N}$ é o número total de indivíduos.

Com base nos dados de frequência foi possível obter o valor de maior proporção da espécie com maior número de indivíduos. Para tanto foi aplicado o cálculo de dominância de Berger-Parker, calculado através da equação a seguir:

$\mathrm{d}=\mathrm{N}_{\max } / \mathrm{N}^{\mathrm{T}}, \mathrm{m}$

onde $\mathrm{N}_{\max }$ é o número de indivíduos da espécie mais abundante

$\mathrm{N}^{\mathrm{T}}$ é o número total de indivíduos na amostra. 
As classes de porte dos indivíduos seguiram a classificação realizada por Mascaró e Mascaró (2005), que considerado pequeno porte a altura $\leq 6 \mathrm{~m}$ e diâmetro da copa $\leq 4$ m; médio porte com altura de 6 - $10 \mathrm{~m}$, com copa entre 4 - $6 \mathrm{~m}$; e grande porte com altura $\geq 10 \mathrm{~m}$ e copa com dimensões acima de $6 \mathrm{~m}$.

O diâmetro a altura do peito (DAP), que é a medida da circunferência do tronco da árvore em metros, foi obtida em campo com auxílio da trena, a uma altura de 1,30 m em relação ao solo, calculada através da medida de perímetro altura do peito (PAP).

O diâmetro da copa (A) foi obtido através da soma dos raios coletados em campo com auxílio da trena, e a sua área total através da equação:

$$
a=\left(\Pi x d^{2}\right): 4
$$

O resultado foi alcançado através da equação:

$$
\text { dap }=\text { cap: } \Pi
$$

O percentual de cobertura vegetal (PVC) foi calculado conforme metodologia utilizada por Araújo, Nóbrega, Silva e Vieira (2015), em que se calcula a soma de toda a área de cobertura vegetal pela área encontrada, multiplicada por 100.

A altura total da árvore (Harv) foi registrada através de um hipsômetro, marcando o ponto entre o solo e o último galho da copa da planta. Já a altura da primeira bifurcação (Hbif) foi mensurada em metros no espaço entre o colo da planta e a primeira inserção de galho.

A distância entre indivíduos (DI) foi medida com trena, a fim de avaliar supostas competições entre as raízes e/ou copas, ou situações que pudessem prejudicar a mobilidade de pedestres, e competições entre as mesmas. As distâncias mínimas permitidas são de 5 metros para pequeno porte, 8 meros para médio porte e 10 metros para grande porte. Quando os portes das árvores foram diferentes, foi empregada a média aritmética das distâncias utilizadas para cada porte (São Paulo, 2005). Contudo, segundo Araújo e Araújo (2016) essas medidas podem variar conforme a característica de cada cidade e largura dos lotes, que conforme o autor pode chegar em 7 metros para pequeno porte; 10 metros para médio e 15 metros para espécies de grande porte.

Para a avaliação de potenciais conflitos entre as árvores e a infraestrutura urbana, foram conferidas com trena as distâncias até a parede ou muro da edificação, poste de iluminação, esquina, garagem, rede de água, rede de esgoto e placa de sinalização. Além das distâncias foram verificadas também o posicionamento da árvore em relação a rede elétrica, da copa em relação à edificação, a condição físico-sanitária da árvore, a área livre da planta (canteiro), sistema radicular e aspecto da poda realizada, conforme metodologia utilizada por São Paulo (2005), CEMIG (2011) e NBR9050 (Associação Brasileira de Normas Técnicas [ABNT], 2015).

As classes de avaliação do posicionamento em relação à rede elétrica consideradas foram:

(1) Presença da rede elétrica com conflito;

(2) Presença da rede elétrica sem conflito;

(3) Ausência de fiação elétrica sobre a planta. 
O posicionamento da copa da árvore em relação à edificação foi avaliado conforme as classes:

(1) Risco de dano com necessidade de supressão;

(2) Risco de dano com necessidade de poda drástica;

(3) Risco de dano com necessidade de poda leve e

(4) Ausência de risco à edificação.

Para a avaliação da condição físico-sanitária da árvore, foram utilizados critérios segundo as classes preconizadas pela CEMIG (2011):

(1) árvore vigorosa, sem sinais de pragas, doenças ou danos;

(2) árvore com vigor médio, podendo apresentar pequenos danos físicos, problemas de pragas ou doenças;

(3) árvore em estágio de declínio e com severos danos de pragas, doenças ou físicos; e

(4) árvore morta ou com morte iminente conforme.

A área livre da planta ou o canteiro destinado à árvore foram mensurados conforme orientações de São Paulo (2005), que correspondeu à relação do diâmetro do troco a 1,3 m do solo e ao local do plantio, em que 0,50 m de DAP deverá corresponder a um canteiro de no mínimo 0,60 m de largura, de acordo tabela realizada pelo autor. Através desses dados, foi possível avaliar a condição do sistema radicular da planta, se este ultrapassava o espaço destinado ao colo e as raízes, ou se apresentava afloramento causando danos.

Por fim, foi avaliada a condição de poda dos indivíduos (CEMIG, 2011):

(1) Sem poda anterior - não está evidente que ocorreu a retirada de galhos;

(2) Poda de limpeza - poda leve sem causar injúrias ou danos ao indivíduo;

(3) Poda drástica - a poda executada desequilibra a árvore, ou com retirada excessiva de galhos, provocando injúria mecânica séria na árvore.

\section{RESULTADOS E DISCUSSÃO}

Foram encontrados nas vias públicas de Almenara, em uma área de 2,37 quilômetros quadrados, 2.038 indivíduos arbóreos distribuídos em ruas, calçadas e canteiros centrais, pertencentes a 61 espécies e 22 famílias botânicas (Tab. 1). As espécies com a maior frequência foram Azadirachta indica A. Juss. (nim-indiano), Senna cf. simea (sena), Licania tomentosa (Benth.) Fritsch (oiti) e Poincianella pluviosa (DC.) L.P. Queiroz (sibipiruna), que juntas totalizaram $52 \%$ de todos os indivíduos.

Foram observadas $61 \%$ de espécies exóticas e 38\% de nativas, sendo apenas 1\% não identificada. Azadirachta indica, conhecida popularmente como nim-indiano, ocupa sozinha $20 \%$ de todo o patrimônio arbóreo da área estudada. Além de ser exótica, de fácil propagação e crescimento rápido, tem tomado proporções invasoras na cidade, podendo promover uma série de danos e desequilíbrio ambiental (Lago, Parlandim, Reis, Pereira, \& Abreu, 2019). Essa espécie muito conhecida pelas suas características fitoterápicas tem sido amplamente utilizada na arborização de ruas da maioria das cidades brasileiras. Na última década sua implantação vem sendo incentivada, principalmente pelo poder público, com 
a livre distribuição de mudas. Segundo Alves (2010), o néctar e o pólen do nim-indiano apresentam toxicidade para adultos e larvas de abelhas Apis melifera.

Além disso, a CEMIG (2011) alerta para o número de indivíduos da mesma espécie, que não deve ultrapassar $10 \%$ do total ao planejar a implantação de árvores no meio urbano, pois o uso da diversidade deve ser encarado sob vários aspectos, tanto da sua origem, hábitos de crescimento, genética e espécie. Ainda segundo o autor, o plantio de uma única espécie em uma mesma área pode ser atrativo do ponto de vista estético, podendo ajudar inclusive nas intervenções de manejo, porém a diversidade de espécies é essencial no planejamento global, pois minimiza a ameaça da perda de vegetação por ataques de pragas.

Tabela 1. Relação de espécies presentes na arborização viária de Almenara, MG.

\begin{tabular}{|c|c|c|c|c|c|}
\hline Tombo & Família/Espécie & Nome comum & Origem & FA & FR $(\%)$ \\
\hline 695 & $\begin{array}{l}\text { ANNONACEAE } \\
\text { Annona squamosa L. }\end{array}$ & pinha & Exótica & 1 & 0,05 \\
\hline 715 & $\begin{array}{l}\text { ANACARDIACEAE } \\
\text { Mangifera indica L. }\end{array}$ & mangueira & Exótica & 6 & 0,29 \\
\hline 700 & Schinus terebinthifolia Raddi & aroeira-vermelha & Nativa & 62 & 3,04 \\
\hline 677 & Schinus molle L. & aroeira-salsa & Nativa & 24 & 1,18 \\
\hline 710 & Spondias mombin L. & cajá & Nativa & 6 & 0,29 \\
\hline 675 & $\begin{array}{l}\text { APOCYNACEAE } \\
\text { Nerium oleander L. }\end{array}$ & espirradeira & Exótica & 23 & 1,13 \\
\hline 674 & Plumeria rubra L. & jasmim-manga & Nativa & 6 & 0,29 \\
\hline 724 & Thevetia peruviana (Pers) K. Schum & chapéu-de-napoleão & Nativa & 10 & 0,49 \\
\hline 730 & $\begin{array}{l}\text { ARECACEAE } \\
\text { Roystonea oleracea (Jacq.) O. F. Cook. }\end{array}$ & palmeira-imperial & Exótica & 9 & 0,44 \\
\hline 741 & $\begin{array}{l}\text { BIGNONEACEAE } \\
\text { Crescentia cujete L. }\end{array}$ & cabaça & Exótica & 1 & 0,05 \\
\hline 685 & $\begin{array}{l}\text { Handroanthus chrysotrichus (Mart. ex DC.) } \\
\text { Mattos }\end{array}$ & ipê amarelo do cerrado & Nativa & 2 & 0,18 \\
\hline 704 & $\begin{array}{l}\text { Handroanthus impetiginosus (Mart. ex DC.) } \\
\text { Mattos }\end{array}$ & ipê rosa & Nativa & 51 & 2,50 \\
\hline 739 & Newbouldia laevis Seem. & akoko & Exótica & 3 & 0,15 \\
\hline 717 & Tabeluia rosealba (Ridl.) Sandwith. & ipê-branco & Nativa & 5 & 0,25 \\
\hline 713 & Tecoma stans (L.) Juss. ex Kunth & ipê-mirim & Exótica & 22 & 1,08 \\
\hline 681 & $\begin{array}{l}\text { CHRYSOBALANACEAE } \\
\text { Licania tomentosa (Benth.) Fritsch }\end{array}$ & oiti & Nativa & 179 & 8,78 \\
\hline 716 & $\begin{array}{l}\text { COMBRETACEAE } \\
\text { Terminalia catappa } \mathrm{L} .\end{array}$ & amendoeira-da-praia & Exótica & 116 & 5,69 \\
\hline 743 & Terminalia mantaly H. Perrier & sete-copas-africana & Exótica & 1 & 0,05 \\
\hline 712 & $\begin{array}{l}\text { EUPHORBIACEAE } \\
\text { Joamnesia princeps Vell. }\end{array}$ & cotieira & Nativa & 22 & 1,08 \\
\hline 729 & $\begin{array}{l}\text { FABACEAE } \\
\text { Adenanthera pavonina Linnaeus. }\end{array}$ & olho-de-pavão & Exótica & 13 & 0,64 \\
\hline 708 & Acacia mangium Willd. & acácia australiana & Exótica & 5 & 0,25 \\
\hline 725 & Albizia lebbeck (L.) Benth. & coração-de-negro & Exótica & 3 & 0,15 \\
\hline
\end{tabular}


continuação

\begin{tabular}{|c|c|c|c|c|c|}
\hline Tombo & Família/Espécie & Nome comum & Origem & FA & FR $(\%)$ \\
\hline 687 & Bauhinia variegata $\mathrm{L}$. & pata-de-vaca-rosa & Exótica & 29 & 1,42 \\
\hline 688 & Bauhinia L. var. candida Roxb. & pata-de-vaca-branca & Nativa & 2 & 0,10 \\
\hline 691 & Cassia fistula L. & chuva-de-ouro & Exótica & 61 & 2,99 \\
\hline 699 & Cassia grandis L..f & cássia-rosa & Nativa & 7 & 0,34 \\
\hline 714 & Clitoria fairchildiana R.A. & sombreiro & Nativa & 17 & 0,83 \\
\hline 686 & Caesalpinia pulcherrima L. & maravilha & Exótica & 22 & 1,08 \\
\hline 721 & Delonix regia (Bojer ex Hook.) Raf. & flamboyant & Exótica & 18 & 0,88 \\
\hline 682 & Erythrina indica Lam. var. picta Hort. & brasileirinha & Exótica & 86 & 4,22 \\
\hline 736 & Inga edulis Mart. & ingá-de-metro & Nativa & 1 & 0,05 \\
\hline 720 & Libidibia ferrea (Mart. ex Tul.) L.P. Queiroz & pau-ferro & Nativa & 18 & 0,88 \\
\hline 705 & $\begin{array}{l}\text { Paubrasilia echinata (Lam.) E. Gagnon, H. Lima } \\
\text { \& G.P. Lewis }\end{array}$ & pau-brasil & Nativa & 1 & 0,26 \\
\hline 735 & Peltophorum dubium (Spreng.) Taub. & canafístula & Nativa & 2 & 0,10 \\
\hline 690 & Poincianella pluviosa (DC.) L.P. Queiroz & sibipiruna & Nativa & 144 & 7,07 \\
\hline 706 & Prosopis juliflora (Sw.) DC. & algaroba & Exótica & 2 & 0,10 \\
\hline 696 & Senna cf. simea (Lam.) H.S. Irwin \& R. Barn. & senna & Nativa & 330 & 16,19 \\
\hline 719 & Samanea tubulosa (Benth.) Barn. \& J.W. Grimes. & sete-cascas & Nativa & 1 & 0,05 \\
\hline 709 & Tamarindus indica $\mathrm{L}$. & tamarindeiro & Exótica & 20 & 0,98 \\
\hline 738 & Platymiscium cf. pubescens Micheli & tamboril-da-mata & Nativa & 1 & 0,05 \\
\hline 731 & $\begin{array}{l}\text { LAURACEAE } \\
\text { Persea americana Mill. }\end{array}$ & abacateiro & Exótica & 1 & 0,05 \\
\hline 680 & $\begin{array}{l}\text { LYTHRACEAE } \\
\text { Lagerstroemia indica L. }\end{array}$ & resedá & Exótica & 2 & 0,10 \\
\hline 684 & Lagerstroemia speciosa Pers. & resedá-gigante & Exótica & 14 & 0,69 \\
\hline 693 & $\begin{array}{l}\text { MALPIGHIACEAE } \\
\text { Malpighia punicifolia L. }\end{array}$ & acerola & Exótica & 2 & 0,10 \\
\hline 689 & $\begin{array}{l}\text { MALVACEAE } \\
\text { Pachira aquatica (DC.) L.P. Queiroz }\end{array}$ & monguba & Nativa & 21 & 1,03 \\
\hline 678 & $\begin{array}{l}\text { MELIACEAE } \\
\text { Azadirachta indica A. Juss. } \\
\end{array}$ & nim-indiano & Exótica & 410 & 20,12 \\
\hline 727 & Melia azedarach $\mathrm{L}$. & cinamomo & Exótica & 3 & 0,15 \\
\hline 701 & $\begin{array}{l}\text { MORACEAE } \\
\text { Ficus benjamina L. }\end{array}$ & ficus & Exótica & 107 & 5,25 \\
\hline 728 & Ficus leprieurii Miq. & figueira-triangular & Exótica & 13 & 0,64 \\
\hline 723 & $\begin{array}{l}\text { MORINGACEAE } \\
\text { Moringa oleifera Lam. }\end{array}$ & moringa & Exótica & 13 & 0,64 \\
\hline 676 & $\begin{array}{l}\text { MYRTACEAE } \\
\text { Psidium guajava L. }\end{array}$ & goiabeira & Exótica & 20 & 0,98 \\
\hline 733 & $\begin{array}{l}\text { Callistemon viminalis (Sol. ex Gaertn.) G. Don ex } \\
\text { Loud. }\end{array}$ & escova de garrafa & Exótica & 1 & 0,05 \\
\hline 694 & Syzygium jambolanum (Lam.) DC. & jambolão & Exótica & 20 & 0,98 \\
\hline
\end{tabular}


conclusão

\begin{tabular}{l|l|l|l|l|l}
\hline Tombo & Família/Espécie & Nome comum & Origem & FA & FR $(\%)$ \\
\hline 742 & $\begin{array}{l}\text { OXALIDACEAE } \\
\text { Averrhoa carambola L. }\end{array}$ & caramboleira & Exótica & 3 & 0,15 \\
\hline 734 & $\begin{array}{l}\text { RUBIACEAE } \\
\text { Ixora finlaysonia Wall. ex G. Don }\end{array}$ & ixora-branca & Exótica & 1 & 0,05 \\
\hline 726 & Morinda citrifolia L. & noni & Exótica & 11 & 0,54 \\
\hline 679 & Mussaenda philippica A. Rich. 'Dona Luz' & mussaenda & Exótica & 4 & 0,20 \\
\hline 692 & $\begin{array}{l}\text { RUTACEAE } \\
\text { Murraya paniculta } \text { (L.) Jacq. }\end{array}$ & murta & Exótica & 52 & 2,55 \\
\hline 737 & $\begin{array}{l}\text { SAPINDACEAE } \\
\text { Sapindus saponaria L. }\end{array}$ & saboneteira & Nativa & 5 & 0,25 \\
\hline 722 & Filicium decipiens (Wight \& Arn.) Thwaites & árvore-samambaia & Exótica & 2 & 0,10 \\
\hline & N/I & - & - & 1 & 0,05 \\
\hline & TOTAL & & & $\mathbf{2}, 038$ & $\mathbf{1 0 0}$ \\
\hline
\end{tabular}

Nota: FA: Frequência absoluta; FR: Frequência relativa. N/I: Espécie não identificada.

Dentre os oito bairros estudados, o que apresentou maior percentual de espécies exóticas em relação às nativas foi o Bairro São Judas Tadeu, com $65 \%$ de espécies exóticas. Apenas o Bairro Tereza Cristina apresentou maior percentual de nativas (54\%) em relação a de exóticas (Fig. 2). Contudo Damaceno, P. Neto, Carard, Cunha, Reis e Caxambu (2017) salientam que, o fato de ser nativa não garante que a árvore será adequada à arborização urbana. É o caso das espécies Poincianella pluviosa (sibipiruna) que, segundo o autor, não é indicada em projeto de arborização por causar alguns conflitos com a infraestrutura urbana como danos a passeios públicos, e Schinus molle (aroeira-salsa) em função da sua eventual toxicidade.

Figura 2. Distribuição por bairros da riqueza de espécies na arborização viária de Almenara, MG.

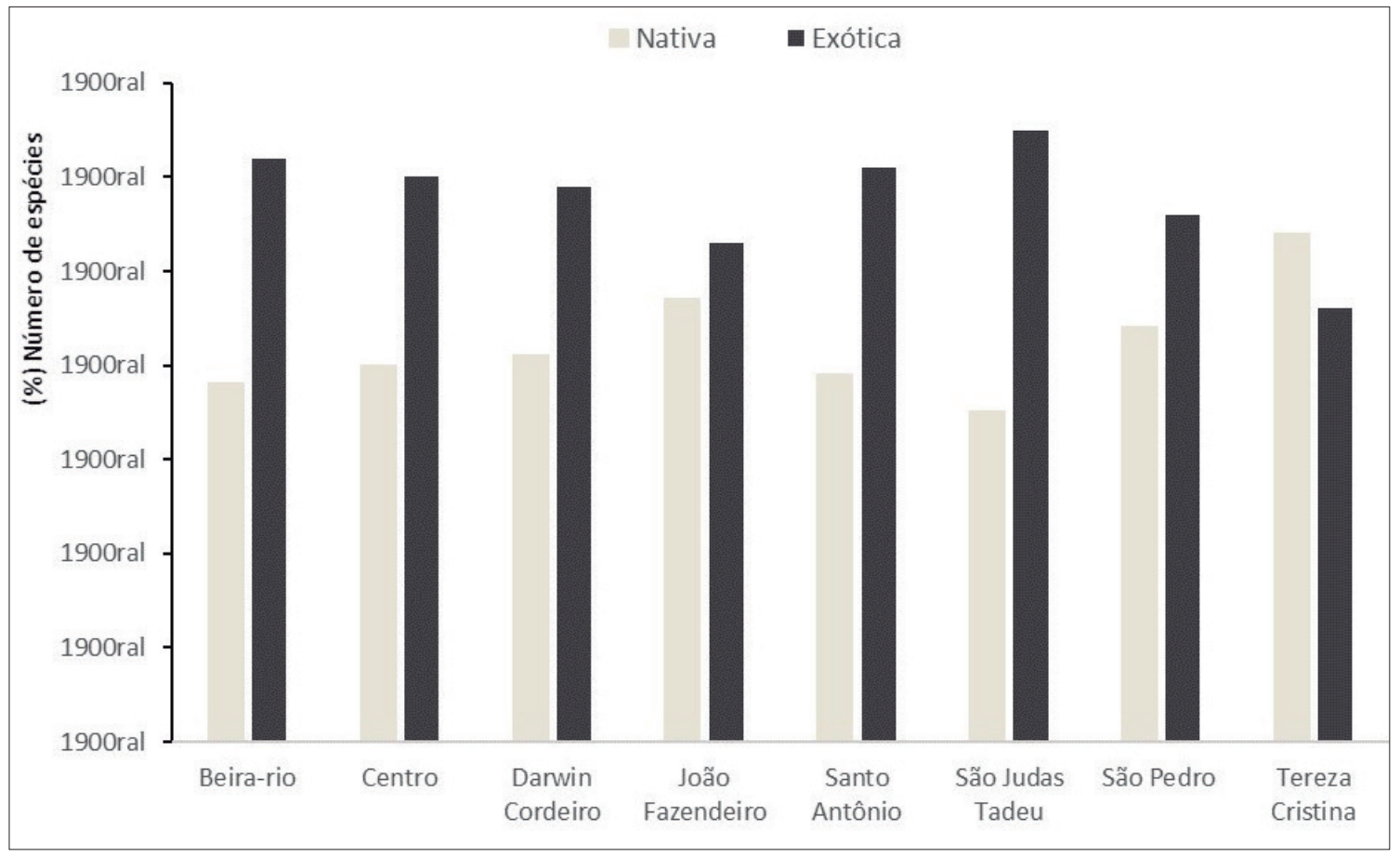




\section{DISTRIBUIÇÃO ESPACIAL DAS ÁRVORES NO AMBIENTE}

Em Almenara, 56\% das árvores estão dispostas nas ruas, no leito carroçável, enquanto $37 \%$ estão localizadas nas calçadas, e $7 \%$ estão localizadas em canteiros centrais, locais destinados a projetos de arborização e paisagismo, comumente conceituados de áreas verdes (Tab. 2). Os bairros com maior percentual de árvores localizadas no leito carroçável são o Beira-rio com $73 \%$, e São Judas Tadeu com $86 \%$, este que conta com a segunda maior frequência de indivíduos de nim-indiano, que por crescer rápido e com facilidade, atraem o interesse da população.

Observa-se, portanto que a maioria das árvores da cidade está disposta em local inadequado, prejudicando a visibilidade do condutor e causando danos à infraestrutura urbana. A média de largura das calçadas da cidade é de 1,65 m, contrariando as recomendações da NBR-9050 (ABNT, 2015) que é de no mínimo 1,90 m, pois o espaço destinado aos pedestres e cadeirantes deve ser de no mínimo 1,20 m. Pode-se concluir que o morador, ao verificar a escassez de espaço em sua calçada, acaba por plantar a árvore no leito carroçável, sem as informações mínimas necessárias que deveriam ser fornecidas pela gestão municipal. Ao invés de oferecer um benefício ambiental à cidade, acarretam transtornos à gestão e a mobilidade urbana.

Das árvores localizadas nas calçadas, $79 \%$ estão posicionadas rente ao meio fio, um procedimento considerado correto (São Paulo, 2005; CEMIG, 2011). Porém, como apenas $26 \%$ delas possuem largura igual ou superior a $1,90 \mathrm{~m}$ percebe-se que ainda que a intenção do morador em posicionar a muda rente ao meio fio seja válida, o espaço destinado ao pedestre fica comprometido.

Tabela 2. Espacialização das árvores no ambiente em Almenara, MG.

\begin{tabular}{|c|c|c|c|c|c|c|c|c|c|c|}
\hline \multicolumn{3}{|c|}{ Áreas } & \multicolumn{8}{|c|}{$\begin{array}{c}\text { Distribuição espacial no } \\
\text { ambiente }\end{array}$} \\
\hline \multicolumn{9}{|c|}{ Árvores das calçadas (\%) } & \multicolumn{2}{|c|}{ Medidas calçadas } \\
\hline Bairros & Área $\left(\mathrm{km}^{2}\right)$ & Narv. & $\mathbf{R}(\%)$ & C.c $(\%)$ & Calç. (\%) & Rmf & Redif & Cvia & MlarC & Calç. $\geq 1,90(\%)$ \\
\hline Beira-rio & 0,15 & 66 & 73 & 0 & 27 & 50 & 0 & 50 & 1,71 & 17 \\
\hline Centro & 0,68 & 480 & 45 & 14 & 41 & 96 & 0 & 4 & 1,62 & 26 \\
\hline Darwin Cordeiro & 0,16 & 280 & 32 & 13 & 67 & 57 & 26 & 17 & 1,90 & 66 \\
\hline João Fazendeiro & 0,20 & 107 & 39 & 0 & 61 & 88 & 0 & 12 & 1,58 & 18 \\
\hline Santo Antônio & 0,25 & 281 & 46 & 16 & 38 & 68 & 3 & 29 & 1,70 & 33 \\
\hline São Judas Tadeu & 0,43 & 352 & 86 & 0 & 14 & 69 & 17 & 14 & 1,52 & 10 \\
\hline São Pedro & 0,35 & 403 & 58 & 16 & 26 & 38 & 14 & 48 & 1,57 & 17 \\
\hline Tereza Cristina & 0,15 & 69 & 67 & 0 & 33 & 96 & 0 & 4 & 1,60 & 19 \\
\hline Total & 2,37 & 2038 & 56 & 7 & 37 & 79 & 15 & 6 & 1,65 & 26 \\
\hline
\end{tabular}

Nota: Narv: Número de indivíduos; R: Rua; C.c: Canteiro central; Calç: Calçada; Rmf: rente ao meio fio; Redif: rente à edificação; Cvia: centro da via; MlarC: largura média das calçadas; Calç. $\geq 1,90$ : Calçadas com largura igual ou superior a 1,90 m.

O Bairro Darwin Cordeiro conta com a melhor relação de mobilidade de pedestres, pois possui o maior percentual de árvores posicionadas nas calçadas (67\%) e a melhor média 
de largura $(1,90 \mathrm{~m})$, sendo que $66 \%$ destas possuem medidas que atendem a recomendação. Já o Bairro São Judas Tadeu, além de ter o menor número de árvores nas calçadas $(14 \%)$, conta com a pior média de largura $(1,52 \%)$, e o menor número de calçadas dentro da norma $(10 \%)$. Novamente, é possível que os moradores optem pelo leito carroçável devido a escassez das calçadas, e por isso o bairro é o mais problemático nesse quesito. A regulamentação de calçadas na cidade de Almenara está prevista na revisão do Plano Diretor do Município, em 2020, com a implantação do Plano de Gestão de Mobilidade Urbana, com processo já em andamento.

\section{Aspectos dendrométricos}

Em relação ao porte das árvores, predominaram espécies de grande porte em todos os bairros estudados, com média de $61 \%$, o que expressa falta de critério na escolha levando em consideração a largura média das calçadas. O Bairro São Judas Tadeu com a menor média de largura de calçada $(1,52 \mathrm{~m})$ revelou $56 \%$ de espécies de grande porte (Fig. 3). Para Benatti, Tonello, Adriano, Silva, Oliveira, Rolim et al. (2012), o uso de espécies de grande porte na arborização de calçadas expressa maior relevância e eficiência em relação às espécies de pequeno porte ou arbustos, porém, deve-se considerar a aplicação de técnicas necessárias ao plantio para que não ocorram problemas causados pelas raízes que possam afetar inclusive a sanidade dos indivíduos arbóreos.

Figura 3. Distribuição do porte das espécies na arborização viária de Almenara, MG.

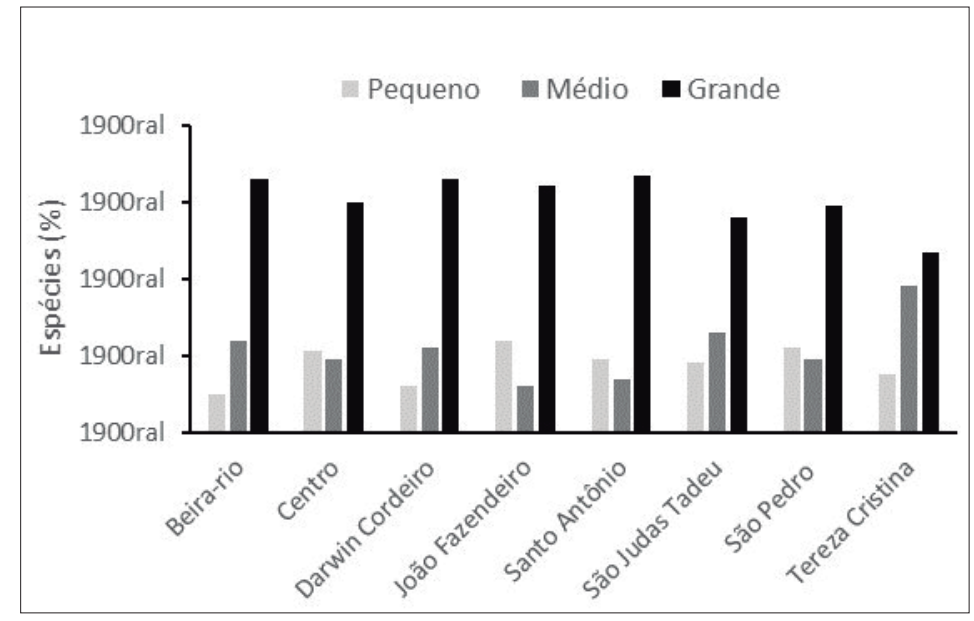

O DAP apresentou resultados bastante heterogêneos, com média geral de 0,29 m, sendo a menor para o Bairro Darwin Cordeiro (0,13 m), e maior para João Fazendeiro, com média de 0,63 m (Fig. 4a). O número de árvores que apresentou DAP menor que $35 \mathrm{~cm}$ foi extremamente alto em Almenara, chegando a 95\% no Bairro Darwin Cordeiro e $92 \%$ no São Judas Tadeu. A predominância de DAP menor que $35 \mathrm{~cm}$ pode indicar a ocorrência de indivíduos jovens, ainda em fase de desenvolvimento (Silva, Leite, \& Tonello, 2015). A média de altura total das árvores é de 5,77 m (Fig. 4c). Dado que também pressupõe grande ocorrência de árvores jovens em toda área da pesquisa. $\mathrm{O}$ alto índice de árvores recém-plantadas reflete o pleno desenvolvimento da cidade de Almenara, com a abertura 
de novas ruas e bairros. Além do acelerado crescimento, as altas temperaturas verificadas nos últimos anos têm levado a população a plantar árvores em frente à sua residência.

A média de diâmetro da copa foi de 5,16 m, apresentado também grande disparidade entre os bairros, a exemplo do Tereza Cristina onde foi encontrada a menor média de diâmetro da copa entre todos com 3,72 m, contrariamente ao Bairro Beira Rio, com a maior 6,40 m (Fig. 4b). Segundo Carcereri, Biondi e Batista (2016) a avaliação da área de projeção da copa possibilita um reconhecimento do ambiente ocupado pelas árvores, permitindo a adequação entre o espaço disponível e o que deve existir entre as árvores, viabilizando a informação quantitativa de área verde em $\mathrm{m}^{2}$ correspondida pela arborização.

Figura 4. Parâmetros da arborização viária de Almenara, MG. a. Média de diâmetro a altura do peito; b.

Média de diâmetro da copa; c. Média de altura total; d. Média de altura de primeira bifurcação.

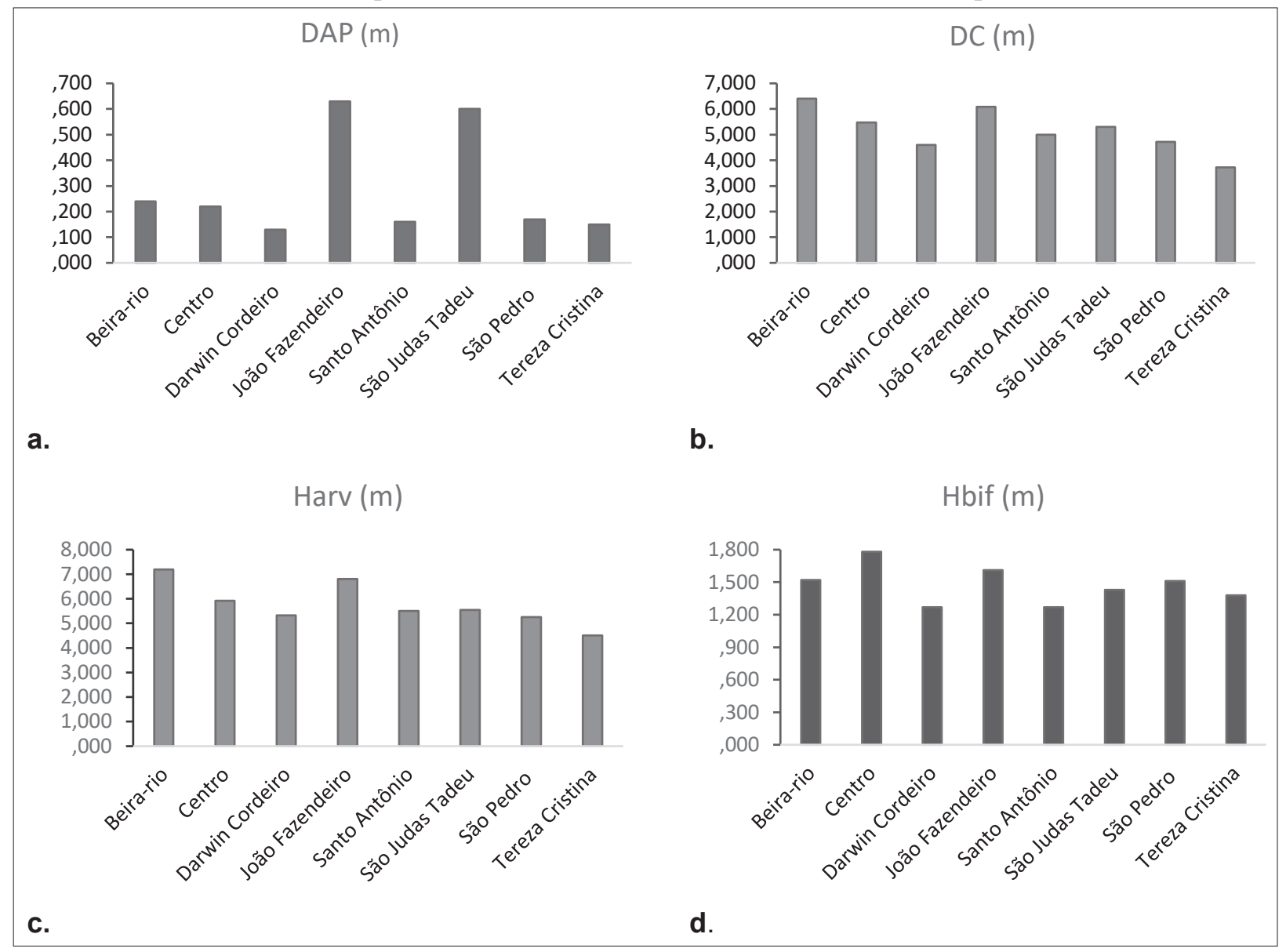

A altura de primeira bifurcação apresentou média geral de $1,47 \mathrm{~m}$ (Fig. 4d). Esse resultado pode indicar referência de qualidade das mudas bem como a existência de podas de formação. Portanto, o resultado foi muito abaixo do recomendado por autores, que recomendam altura mínima de $1,80 \mathrm{~m}$, de maneira que os galhos não interfiram no trânsito de pedestres (Sampaio, 2006; Martini, Gaspar, \& Biondi, 2014). A menor média foi verificada nos Bairros Darwin Cordeiro e Santo Antônio (1,27 m) e justifica-se pela falta de manejo e tratos culturais, como podas de condução e limpeza. Situação que, ainda segundo os autores, deve ser trabalhada preferencialmente no viveiro, visando a melhor formação estrutural do fuste e a correta condução da copa, melhorando as condições de mobilidade 
do pedestre. As espécies Azadirachta indica (nim-indiano) com $84 \%$, e Licania tomentosa (oiti) com $63 \%$, apontaram as maiores percentagens de indivíduos com as características de Hbif menor que $1,80 \mathrm{~m}$ (Fig. 5).

\section{CONDIÇÃO FITOSSANITÁRIA DA ÁRVORE}

Foram diagnosticados problemas físicos e sanitários, além de sinais de injúrias e depredação em $48 \%$ das árvores encontradas. O quadro geral apresentou $32 \%$ com vigor médio, pequenos sinais de pragas e/ou doenças; $13 \%$ em estágio de declínio, com severos danos de pragas, doenças ou físicos; e 3\% estavam mortas ou com morte iminente.

A área que apresentou a menor percentagem de árvores vigorosas foi o BairroCentro, com $28 \%$ dos casos, supostamente por ser a área mais antiga, com maior tráfego de veículos, além de maior número de instrumentos e mobiliários urbanos, fazendo com que houvesse grande volume de podas e manejos inadequados com indivíduos de espécies como sibipiruna, sena e oiti, onde foi encontrada maior presença de cupins.

Segundo Zamproni et al. (2018), a árvore sibipiruna costuma não demonstrar bom desempenho na arborização de vias públicas, mas por ser uma espécie muito utilizada, necessita de cuidados especiais de manutenção e manejo. Em seu trabalho no município de Bonito (MS), 54,5\% foram atacadas por cupins, o que denota condição sanitária ruim, idade avançada e injúrias sofridas pela população (Duarte et al., 2018).

Em Almenara, as espécies que apontaram maior percentagem de árvores com problemas sanitários foram Erythrina indica (brasileirinha), com $71 \%$, e sibipiruna com $52 \%$, sendo 56 indivíduos em fase de declínio, com problemas de pragas e doenças e 17 indivíduos mortos ou com morte iminente (Fig. 5).

Figura 5. Principais conflitos entre as espécies de maior frequência na arborização viária de Almenara, MG.

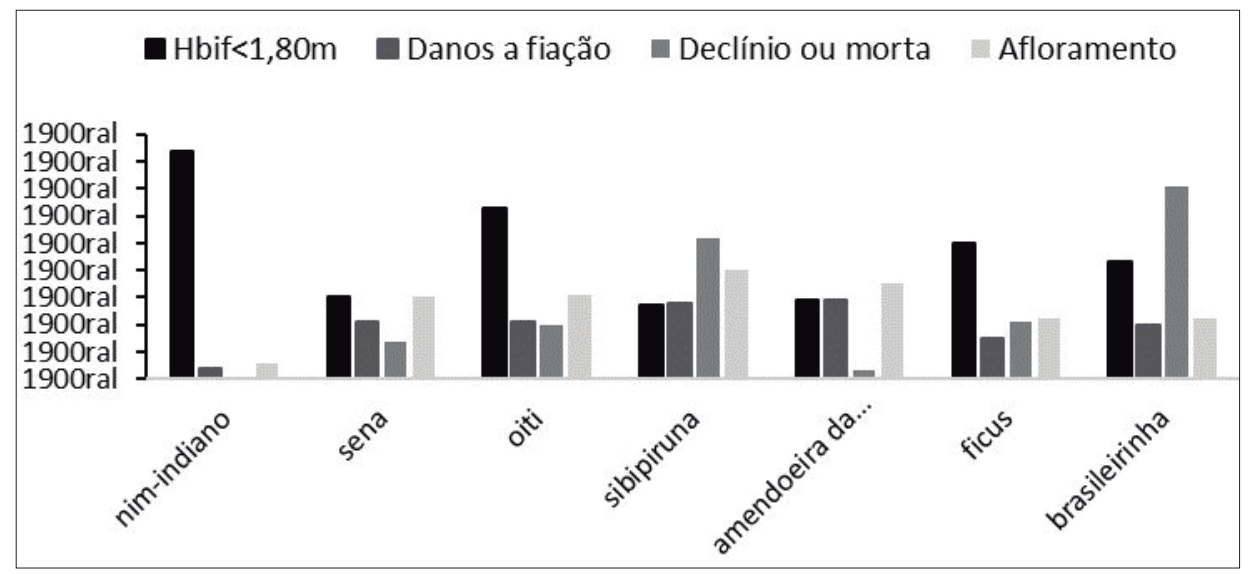

\section{Conflitos com a infraestrutura urbana}

Para que haja boa conformidade de adaptação entre os indivíduos arbóreos e o ambiente construído, é necessária a adoção de critérios para adequada locação da planta, a fim 
de evitar futuros conflitos entre as árvores e a infraestrutura urbana (Martins, Andrade, Hanisch, De Angelis, \& Caxambu, 2011). Objetivando analisar os resultados apresentados nessa pesquisa foram analisados critérios e recomendações estabelecidas por (CEMIG, 2011; São Paulo, 2005; ABNT - NBR9050, 2015) a fim de avaliar os supostos conflitos gerados pela disputa de espaço entre as árvores e a infraestrutura urbana (Tabs. 3 e 4).

Tabela 3. Posicionamento e sanidade dos indivíduos arbóreos nas vias de Almenara, MG.

\begin{tabular}{|c|c|c|c|c|c|c|c|c|c|c|c|c|}
\hline \multirow{2}{*}{ Áreas (Bairros) } & \multirow{2}{*}{$\mathbf{N}$} & \multicolumn{3}{|c|}{ PRE (\%) } & \multicolumn{4}{|c|}{ PCE (\%) } & \multicolumn{4}{|c|}{ CFA (\%) } \\
\hline & & 1 & 2 & 3 & 1 & 2 & 3 & 4 & 1 & 2 & 3 & 4 \\
\hline Beira-rio & 66 & 9 & 12 & 79 & 2 & 2 & 23 & 74 & 38 & 48 & 12 & 2 \\
\hline Centro & 480 & 16 & 21 & 63 & 2 & 1 & 26 & 71 & 28 & 48 & 20 & 4 \\
\hline Darwin Cordeiro & 280 & 10 & 21 & 69 & 2 & 0 & 12 & 86 & 76 & 19 & 5 & 0 \\
\hline João Fazendeiro & 107 & 29 & 10 & 51 & 4 & 0 & 34 & 63 & 27 & 38 & 25 & 9 \\
\hline Sto. Antônio & 281 & 19 & 28 & 53 & 0 & 0 & 17 & 83 & 67 & 18 & 12 & 4 \\
\hline S. Judas Tadeu & 352 & 17 & 32 & 51 & 2 & 0 & 29 & 68 & 60 & 30 & 9 & 1 \\
\hline S. Pedro & 403 & 18 & 32 & 50 & 3 & 1 & 25 & 72 & 55 & 30 & 12 & 3 \\
\hline Tereza Cristina & 69 & 1 & 19 & 80 & 0 & 0 & 15 & 86 & 54 & 25 & 14 & 7 \\
\hline TOTAL & 2038 & 16 & 25 & 59 & 2 & 0 & 23 & 75 & 52 & 32 & 13 & 3 \\
\hline \multirow{2}{*}{ Áreas (Barrios) } & \multirow{2}{*}{$\mathbf{N}$} & \multicolumn{3}{|c|}{ CEL (\%) } & \multicolumn{3}{|c|}{ CSR (\%) } & \multicolumn{4}{|c|}{ APS (\%) } & \\
\hline & & 1 & 2 & 3 & 1 & 2 & 3 & 1 & 2 & 3 & 4 & \\
\hline Beira-rio & 66 & 5 & 15 & 80 & 55 & 18 & 27 & 17 & 59 & 30 & 12 & \\
\hline Centro & 480 & 10 & 71 & 20 & 56 & 7 & 37 & 15 & 52 & 27 & 11 & \\
\hline Darwin Cordeiro & 280 & 39 & 26 & 35 & 78 & 14 & 8 & 8 & 57 & 16 & 10 & \\
\hline João Fazendeiro & 107 & 0 & 29 & 71 & 33 & 27 & 40 & 16 & 68 & 19 & 11 & \\
\hline Sto. Antônio & 281 & 18 & 32 & 51 & 76 & 5 & 19 & 15 & 53 & 41 & 6 & \\
\hline S. Judas Tadeu & 352 & 4 & 21 & 75 & 63 & 12 & 25 & 8 & 57 & 22 & 9 & \\
\hline S. Pedro & 403 & 5 & 33 & 62 & 66 & 19 & 15 & 17 & 42 & 31 & 17 & \\
\hline Tereza Cristina & 69 & 10 & 20 & 70 & 55 & 25 & 20 & 4 & 48 & 33 & 14 & \\
\hline TOTAL & 2038 & 13 & 37 & 50 & 63 & 13 & 24 & 13 & 53 & 27 & 11 & \\
\hline
\end{tabular}

Nota: N: número de árvores; PRE: posicionamento da árvore em relação à rede elétrica: (1) em conflito, (2) sem conflito, (3) ausência de fiação elétrica sobre a planta; PCE: posicionamento da copa da árvore em relação à edificação: (1) risco de dano com necessidade de supressão, (2) risco de dano com necessidade

de poda drástica, (3) risco de dano com necessidade de poda leve; (4) ausência de risco à edificação; CFA: condição fitossanitária da árvore: (1) vigorosa, (2) árvore com vigor médio, (3) árvore em estágio de declínio, (4) árvore morta ou com morte iminente; CEL: condição do espaço livre da planta: (1) adequado,

(2) inadequado, (3) ausência de caixa ou colo edificado; CSR: condição do sistema radicular: (1) raiz totalmente subterrânea, (2) raiz de forma superficial só na área de crescimento da árvore, (3) afloramento de raiz para fora do espaço destinado à árvore; APS: tipo de poda sofrida: (1) poda elétrica, (2) poda edificação, (3) sem poda anterior; (4) poda drástica.

\section{Posicionamento da árvore em relação à rede elétrica}

Sabe-se que a convivência harmônica entre redes de distribuição elétrica e a arborização viária é um grande desafio para as prefeituras e concessionárias de energia nos diversos estados brasileiros, e o manejo entre estes é de grande interesse, pois lida com benefícios inegáveis à população e ao meio ambiente (Oliveira et al., 2016; Lima et al., 2016). Quanto a isso, foi verificado nessa pesquisa que $41 \%$ das árvores encontravam-se posicionadas sob 
a rede a rede elétrica. Destas, $16 \%$ apresentaram algum conflito que pudesse causar danos à fiação. Observou-se em Almenara que 71\% das árvores posicionadas sob a rede elétrica são de grande porte. As espécies Terminalia catappa (amendoeira-da-praia) e Poincianella pluviosa (sibipiruna) apontaram os maiores percentuais de indivíduos que conflitavam com a rede elétrica podendo causar algum dano, com 29\% e 28\% respectivamente. Quanto maior o porte arbóreo maior a sua interferência com a rede elétrica, nesse caso a CEMIG (2011) enfatiza que sob a rede elétrica só se recomenda a utilização de espécies de pequeno porte. No entanto, como a maioria desses indivíduos estão em desenvolvimento, ainda não apresentaram conflitos e tal condição será apresentada no futuro, caso não haja planejamento na condução de manejo e orientação para frear a implantação de espécies de grande porte sob a rede elétrica.

Quanto a distância entre a árvore e o poste de iluminação, foi verificado que 9\% de todas as árvores encontradas não obedecia a recomendação de CEMIG (2011), com distância mínima de 4 metros (Tab. 4). Nesse caso, indivíduos bloqueavam a iluminação pública com risco de ainda causar danos ao sistema elétrico através da copa, além de prejudicar a visibilidade da sinalização. Com 14\%, o Bairro São Pedro foi a área onde ocorreu o maior percentual de casos.

Tabela 4. Percentagem de indivíduos arbóreos, por bairros, em conflito no município de Almenara, MG.

\begin{tabular}{cccccccccc}
\hline Áreas (Bairros) & $\mathbf{N}$ & DI (\%) & DE (\%) & DP (\%) & DEs (\%) & DG (\%) & DRA (\%) & DRE (\%) & DPS (\%) \\
\hline Beira-rio & 66 & 38 & 29 & 6 & 0 & 6 & 21 & 18 & 0 \\
Centro & 480 & 15 & 24 & 6 & 1,5 & 10 & 18 & 15 & 2 \\
Darwin Cordeiro & 280 & 37 & 15 & 3 & 1,4 & 9 & 23 & 17 & 0 \\
João Fazendeiro & 107 & 36 & 41 & 12 & 0,9 & 12 & 12 & 13 & 1 \\
Santo Antônio & 281 & 33 & 26 & 9 & 1 & 6 & 23 & 15 & 0 \\
São Judas Tadeu & 352 & 41 & 8 & 10 & 1,4 & 13 & 26 & 20 & 0 \\
São Pedro & 403 & 35 & 21 & 14 & 6 & 10 & 23 & 19 & 0 \\
Tereza Cristina & 69 & 46 & 22 & 1 & 4 & 7 & 29 & 20 & 1 \\
\hline Total & $\mathbf{2 0 3 8}$ & $\mathbf{3 2}$ & $\mathbf{2 1}$ & $\mathbf{9}$ & $\mathbf{2}$ & $\mathbf{1 0}$ & $\mathbf{2 2}$ & $\mathbf{1 7}$ & $\mathbf{1}$
\end{tabular}

Nota: N: número de indivíduos; DI: distância entre indivíduos; DE: distância da parede ou muro da edificação; DP: distância do poste de iluminação; DEs: distância da esquina; DG: distância da garagem; DRA: distância da rede de água; DRE: distância da rede de esgoto sanitário; DPS: distância da placa de identificação e sinalização.

\section{Posicionamento da árvore em relação à edificação}

A proximidade da árvore em relação à edificação, fora dos padrões CEMIG (2011), pode causar danos ao muro, parede e telhado. A pesquisa revelou que $21 \%$ das árvores estavam posicionadas numa distância inferior a 1,20 m da edificação, podendo oferecer algum risco ao mobiliário, além de dificultar a mobilidade urbana.

Sobre o posicionamento da copa, $3 \%$ das árvores encontravam-se oferecendo risco à edificação com necessidade de poda leve para melhor formação da copa em função do contato com a edificação. Apenas em $2 \%$ de todas as árvores havia necessidade de poda drástica e/ ou supressão, e 75\% não apresentaram nenhum risco à edificação. A proximidade 
entre indivíduos também pode oferecer risco à edificação, visto que a as copas podem se encontrar e escurecer o ambiente. Nessa pesquisa foi diagnosticado que 32\% das árvores encontradas estavam com distância inferior à recomendada por São Paulo (2005). Em decorrência disso, indivíduos concorriam entre si pelo espaço de crescimento de raízes e copas, suscetíveis a podas e consequentes ataques de pragas e doenças.

Foram verificados conflitos com as redes de abastecimento de água e esgoto de $22 \%$ e $17 \%$ respectivamente. Na pesquisa foi avaliado o conflito em relação à distância e não ao dano, onde o recomendado é um mínimo de 2 metros de distância para ambos (CEMIG, 2011).

Com relação a garagens foi verificado que 10\% das árvores se encontravam em conflito com entrada e saída de veículos, ainda que esta seja mantida no local por oferecer sombra para o veículo e para a edificação, além da função estética.

\section{Condição do espaço livre da planta e do sistema radicular}

A área livre destinada à planta (canteiro) deve corresponder ao diâmetro do tronco da espécie a ser implantada a 1,3 $\mathrm{m}$ do solo. E o espaço destinado ao plantio deve variar entre 0,70 m e 1,20 m de largura.

Em Almenara foi verificado que esse quesito revelou alto percentual de conflitos, sendo $37 \%$ apresentando espaço inadequado, ou seja, havia presença de canteiro, porém inadequado ao porte; e em 50\% não havia canteiro e o colo apresentava-se edificado. Resultado ainda maior que o encontrado por Martins et al. (2011) em Luiziana (PR), onde em 38\% das árvores faltava canteiro. A ausência de canteiros e/ou canteiros mal dimensionados, não permitem o bom desenvolvimento do sistema radicular da planta, o que gera estrangulamento do caule, dificultando a circulação da seiva e favorecendo o afloramento de raízes, situação mais frequente em espécimes de médio e grande porte (Santos \& Teixeira, 2001).

A ausência de área livre para o crescimento do colo das árvores impede a penetração de água e nutrientes forçando o afloramento de raízes em busca de alimentos, exercendo pressão sobre o piso do calçamento e da edificação, prejudicando o trânsito de pedestres e portadores de mobilidade reduzida. Quanto maior a área do canteiro melhor o desenvolvimento das árvores e a compatibilidade com a calçada (Santos \& Teixeira, 2001; São Paulo, 2015).

Quanto à condição do sistema radicular, foi verificado que 13\% possuíam raízes superficiais, só na área de crescimento da árvore; e 24\% apresentaram afloramento causando danos ao calçamento. Resultados semelhantes foram encontrados por autores em cidades de pequeno porte, como os de Rivelini e Gomes (2017) em Araçatuba (SP) com 32,4\%; Martins et al. (2011) em Luiziana (PR) com 23\%, e Periotto (2016) em Medianeira (PR) com 18,5\%. Este último ressalta que tais resultados sinalizam a falta de planejamento na escolha das espécies, não respeitando a sua biologia e hábito de crescimento.

Em Almenara, quase todas as espécies apresentaram índices de afloramento igual ou superior a 30\% (sibipiruna 40\%, amendoeira-da-praia 35\%, oiti 31\% e sena 30\%). Das espécies 
de maior frequência de indivíduos, apenas o nim-indiano apontou baixo conflito (Fig. 5), supostamente pelo fato da população dessa espécie ainda não se encontrar na fase adulta.

Em face ao exposto, está bastante evidente nessa pesquisa que o elevado índice de afloramento de raízes nas árvores de Almenara está relacionado a baixa percentagem de presença de canteiro adequados ao porte (13\%), e a baixa percentagem de calçadas compatíveis com arborização, independente do porte $(26 \%)$.

\section{Condição da árvore em relação à poda sofrida}

A expressão 'podar' tem origem do latim pu-tare, e quer dizer limpar, ou seja, é o conjunto de cortes executados numa árvore a fim de adequar o indivíduo ao ambiente, ou regularizar a sua produção (Lemos; Machado, \& Jacob Neto, 2016). Muitas vezes a poda decorre dos conflitos gerados entre o indivíduo arbóreo, edificação e rede elétrica. Portanto a poda executada de forma correta pode minimizar os conflitos com os equipamentos urbanos e tornar a arborização viável à população, permitindo melhor aproveitamento dos seus benefícios (Lemos, Machado, \& Jacob Neto, 2016; Rivelini \& Gomes, 2017).

Para isso existem critérios a serem observados anteriormente à realização da poda, como observar as características e arquitetura da copa, bem como as suas exigências ecológicas (Vaz \& Rocabado, 2018). A CEMIG (2011) alerta que as podas irregulares podem causar sérios danos à arquitetura da planta, influenciando drasticamente a sua fisiologia, trazendo graves consequências à sanidade da árvore.

Em Almenara $13 \%$ das podas ocorreram em função do conflito da árvore com a rede elétrica, $53 \%$ ocorreram em decorrência do conflito gerado entre a copa da árvore e a edificação, e $11 \%$ das podas executadas tinham provocado desequilíbrio por terem sidos retirados galhos em excesso, provocando injúria mecânica séria na árvore. Apenas $27 \%$ das árvores encontradas não apresentavam sinais de podas recentes.

A quantidade de árvores da cidade que passaram por processo de poda é bastante elevado, e ao que parece essas podas não teriam sido executadas pela concessionária de energia ou servidores da Prefeitura, visto que os danos causados aos indivíduos arbóreos são bastante evidentes. A poda executada por aquele que não passou por curso ou treinamento pode oferecer risco à integridade física da planta. Além disso, a prática realizada sem o conhecimento e permissão da Secretaria de Meio Ambiente do município pode causar danos ao indivíduo, configurando crime ambiental previsto na Lei de Crimes Ambientais (Lei no 9.608/1998), descrito no Código de Posturas da cidade, Art. 46, "É proibido podar, cortar, danificar, derrubar, remover ou sacrificar árvores da arborização pública, sendo estes serviços de atribuição exclusiva da Prefeitura, obedecidas as disposições do Código Florestal Brasileiro" (Lei n $\left.{ }^{\circ} 612,1990\right)$.

Com base no exposto, orientações sobre o comportamento da população em relação ao patrimônio natural da cidade, planejamento e manejo da arborização urbana, devem ser realizadas nas principais vias de comunicação, como estabelecimentos de ensino, imprensa falada e escrita, para que as interferências da população para com o manejo da arborização sejam regularizadas. 


\section{Distâncias da árvore para esquinas e placas de sinalização}

Esses parâmetros foram considerados irrelevantes, com resultado de $2 \%$ e $1 \%$. Normalmente quando a árvore está posicionada na esquina e muito próxima a uma placa de sinalização, pode vir a obstruir a visibilidade do condutor e do pedestre no trânsito. A pesquisa demonstrou que, além do número de árvores posicionados na esquina ter sido baixo, a cidade apresenta-se pouco sinalizada.

\section{CONSIDERAÇÕES FINAIS}

A arborização em Almenara sofre intervenções regulares da população, e encontra-se em sua maioria em desacordo com as recomendações técnicas, apresentando falhas importantes no planejamento, gestão e manejo. Destaca-se a escolha da espécie inadequada ao local do plantio bem como podas malconduzidas, motivos para vários conflitos no convívio harmônico entre os moradores e a vegetação. Oliveira e Pereira (2010) apontam que ações de conservação da biodiversidade precisam ser realizadas com urgência, pois no cenário atual de degradação abster-se de executar uma ação de manejo pode trazer graves consequências, sendo assim medidas de comunicação social e educação ambiental são importantes no combate aos impactos causados por espécies indesejadas.

A gestão das árvores que estão localizadas no leito carroçável e o alargamento das calçadas estão entre as maiores dificuldades a serem enfrentadas na solução desses conflitos. Devendo-se ter atenção especial a mobilidade urbana, ponderando a possibilidade de substituição e/ou realocação desses indivíduos, envolvendo também a intensificação do manejo de podas.

Recomenda-se que os indivíduos em fase de declínio sejam substituídos, preferencialmente por espécies nativas a fim de contribuir para manutenção da fauna e flora silvestres e melhorar as condições da vegetação em forma de corredores ecológicos, evitando novos plantios de espécies exóticas como o nim-indiano devido ao seu potencial de intoxicação da entomofauna nativa.

Os conflitos gerados entre esses indivíduos arbóreos e os equipamentos e instrumentos urbanos geram em Almenara um grande desafio para o poder público municipal para com o planejamento e a manutenção da vegetação urbana. Há necessidade da atualização do plano diretor e a criação do plano de gestão de arborização urbana da cidade, para que a arborização em vias públicas seja discutida e normatizada.

É importante salientar que a base de dados elaborada poderá servir de apoio na elaboração de um plano de arborização, que a médio e longo prazo pode contribuir para a melhoria da gestão ambiental espacializada em um sistema de informações geográficas, bem como subsidiar ações semelhantes em cidades pequenas com características similares. 


\section{REFERÊNCIAS}

ABNT NBR 9050, de 2015. Acessibilidade a edificações, mobiliário, espaços e equipamentos urbanos. Rio de Janeiro: Associação Brasileira de Normas Técnicas. Recuperado de http://www.ufpb.br/cia/contents/manuais/ abnt-nbr9050-edicao-2015.pdf.

Alves, J.E. (2010). Toxicidade do nim (Azadirachta indica A. Juss.: Meliaceae) para Apis melifera e sua importância apícola na Caatinga e Mata Litorânea cearense. (Doutorado em Zootecnia), Universidade Federal do Ceará UFCE, Fortaleza, CE, Brasil.

Araújo, M.N., Araujo, A.J. de. Arborização Urbana. (2016). Cadernos Técnicos da Agenda Parlamentar, CreaPR. Recuperado de http://177.92.30.55/ws/wp-content/uploads/2016/12/arborizacao-urbana.pdf

Araújo, L.H.B.D., Nóbrega, C.C.D., Silva, A.C.F.D., \& Vieira, F.D.A. (2015). Análise quali-quantitativa da arborização da Praça Pedro Velho, Natal, RN. Agropecuária Científica no Semiárido, 11(1): 65-71.

Benatti, D.P., Tonello, K.C., Adriano Júnior, F.C., Silva, J.M. A. S., Oliveira, I. R., Rolim, E.N. et al. (2012). Inventário arbóreo-urbano do município de salto de Pirapora, SP. Revista Árvore, 36(5), 887- 894.

Biondi, D. (2008). Arborização aplicada à educação ambiental nas escolas. Curitiba: Autor.

Carcereri, V. H., Biondi, D., \& Batista, A.C. (2016). Análise da cobertura arbórea das praças de Curitiba PR. Rev. SBAU, 11(2), 12-26.

Companhia Energética de Minas Gerais (2011). Manual de Arborização. Belo Horizonte.

Damaceno, F.M., P. Neto, S., Carard, R.F., Cunha, C.C., Reis, R.A, \& Caxambu, M.G. (2017). Censo de arborização urbana do município de Mamborê, Paraná. SaBios, Rev. Saúde e Biol.,12(2),10-19.

Duarte, T.E.P.N., Angeoletto. F., Richard, E., Vacchiano, M.C., Leandro, D.S., Bohrer, J.F.C, \& Santos, J.W.M.C. (2017). Arborização urbana no Brasil: um reflexo de injustiça ambiental. Terr@Plural 11(2), 291-303.

Duarte, T.E.P.N., Angeoletto. F., Santos, J.W.M.C., Silva, F.F., Bohrer, J.F.C., \& Massad, L. (2018). Reflexões sobre arborização urbana: Desafios a serem superados para o incremento da arborização urbana no Brasil. Rev. Agro. Amb. 11(1), 327-341.

Fortunato, R.A. (2011). O turismo solidário e a redescrição social no Vale do Jequitinhonha-MG. (Doutorado em Meio Ambiente), Universidade do Estado do Rio de Janeiro - UERJ, Rio de Janeiro, RJ, Brasil.

Gonçalves, A., \& Meneguetti, K.S. (2015). Projeto de arborização como patrimônio da cidade. Ambiente Construído 15(1), 99-118.

Instituto Brasileiro de Geografia e Estatística (2010). Censo 2010. Recuperado de https://censo2010.ibge. gov.br/noticias-censo

Instituto Brasileiro de Geografia e Estatística (2019). Cidades. Recuperado de https:/ / cidades.ibge.gov.br/ $\mathrm{brasil} / \mathrm{mg} /$ almenara/panorama

Imam, A.U., \& Banerjee, U.K. (2016). Urbanization and greening of Indian cities: Problems, practices, and policies. Ambio, 45, 442-457.

Lago, L. S., Parlandim, L.S., Reis, L.O., Pereira, B.C.; \& Abreu, L.P. (2019). Análise quali-quantitativa da arborização de um condomínio horizontal na cidade de Corrente - Piauí (Brasil). Revista Brasileira de Meio Ambiente, 7(2), 29-39.

Lei $n^{0} 1.133$ de 05 mar. 2008. Plano Diretor Municipal da cidade de Almenara.

Lei $n^{0}$ 612, 1990. Código de Posturas da cidade de Almenara.

Lei $n^{0} 9.605$ de 12 de fevereiro de 1998. Lei de Crimes Ambientais. Presidência da República - Casa Civil. Recuperado de http://www.planalto.gov.br/CCivil_03/leis/L9605.htm.

Lei $n^{0} 12.651$ de 07 de julho de 2012. Código Florestal Brasileiro. Presidência da República - Casa Civil. Recuperado de http://www.planalto.gov.br/ccivil_03/_ato2011-2014/2012/lei/112651.htm.

Lemos, J.J., Machado. A.L., \& Jacob Neto, J. (2016). Minimização do processo de poda em árvores utilizadas no paisagismo urbano. Semioses, 10(3), 21-35. Doi:10.15202/1981996X.2016v10n3p21 
Lira Filho, J.A. (2012). Paisagismo: princípios básicos. (Coleção Jardinagem e Paisagismo). Viçosa, MG: Aprenda Fácil.

Manfio, V., \& Benaduce, G.M.C. (2011). A (re) estruturação urbana e o desenvolvimento local da pequena cidade de Nova Palma/RS. Rev. GEOMAE, 2(1), 71-82.

Martini, A., Gaspar, R.G.B., \& Biondi, D. (2014). Diagnóstico da implantação da arborização de ruas no bairro Santa Quitéria, Curitiba - PR. Rev. SBAU, 9(2), 148-167.

Martins, L.F.V., Andrade, H.H.B., Hanisch, R.F., De Angelis, B.L.D., \& Caxambu, M.G. (2011). Análise da Compatibilidade da Arborização Viária com o Ambiente Construído na cidade de Luiziana-PR. Rev. SBAU, 6(3), 103-127.

Mascaró, L.E.A.R., \& Mascaró, J.L. (2005). Vegetação urbana (2a ed.) Porto Alegre: Mais Quatro.

Oliveira, A.E.S., \& Pereira, D.G. (2010). Erradicação de espécies exóticas invasoras: múltiplas visões da realidade brasileira. Desenvolvimento e Meio Ambiente, 21, 173-181.

Oliveira, A. F., Pereira, G. A., Santos, E., Oliveira, K.D.S., Pompermayer, R.S. et al. (2016). Arborização viária conflituosa com a rede elétrica na região oeste de Belo Horizonte-MG. Rev. SBAU, 11(2), 27-44.

Oliveira, M.S., Ferreira, A.W.C., Lopes, J.R.S., Reis, J.R, \& Costa, J. A. (2017). Espécies vegetais presentes em praças e avenidas do município de Aldeias Altas, Maranhão, Brasil. Rev. SBAU, 12(4), 13-22.

Pagliari, S.C., \& Dorigon, E.B. (2013). Arborização urbana: importância das espécies adequadas. Revista Unoesc e Ciência - ACET, 4(2), 139-148.

Periotto, F., Pituco, M.M., Helmann, A.C., Santos, T.O. dos, \& Bortolotti, S.L. (2016). Análise da arborização urbana no município de Medianeira, Paraná. Rev. SBAU, 11(2), 59-74.

Reboita, M.S., Rodrigues M., Silva, L.F., \& Alves, M.A. (2015). Aspectos climáticos do Estado de Minas Gerais. Revista Brasileira de Climatologia, 17, 209-229.

Rivelini, P.M., \& Gomes, M.F. (2017). Análise da arborização viária e sua relação com a infraestrutura urbana na Rua Luiz Pereira Barreto, Araçatuba-SP. Revista Contemporânea: Revista UniToledo: Arquitetura, Comunicação, Design e Educação, 2(1), 88-103.

Sampaio, A.C.F. (2006). Análise da arborização de vias públicas das principais zonas do plano piloto de MaringáPR. (Mestrado). Universidade Estadual de Maringá - UEM, Maringá, PR, Brasil.

Santos, N.R.Z., \& Teixeira, I.F. (2001). Arborização de vias públicas, ambiente X vegetação. Santa Cruz do Sul: Instituto Souza Cruz.

São Paulo. (2005). Manual técnico de arborização urbana. Secretária do verde e meio ambiente.

Silva, T.G., Leite, E.C., \& Tonello, K.C. (2014). Inventário da arborização urbana no município de Araçoiaba da Serra, SP. Rev. SBAU, 9(4), 151-169.

Soares, A.P. (2013). Caracterização gravimétrica dos resíduos sólidos do Baixo Jequitinhonha/Minas Gerais - Instrumento para gestão e gerenciamento de resíduos sólidos urbanos sob perspectiva regional. Anais do Congresso Brasileiro de Gestão Ambiental - ConGeA. Salvador, BA, Brasil, 4. Recuperado de https://www. ibeas.org.br/congresso/congresso4.htm

Trichez, F. (2008). Programa de planejamento ambiental para melhoria das áreas verdes públicas e centrais da cidade de Quilombo, SC. (Monografia de Especialização em Arquitetura de Interiores), Universidade do Oeste de Santa Catarina - UNOESC, Xanxerê, SC, Brasil.

Vaz, G.A.S., \& Rocabado, J.M.A. (2018). Arborização urbana em Praças de Alagoinhas, BA, Brasil. Ambiência, 14(3), 496-512.

Zamproni, K., Biondi, D., Maria, T.R.B.C., \& Louveira, F.A. (2018). Diagnóstico quali-quantitativo da arborização viária de Bonito, Mato Grosso do Sul. Floresta, 48(2), 235-244.

Data de submissão: 12/dez./ 2019

Data de aceite: 13/mar./2020 